\title{
Stochastic dynamic population model of North Sea sandeels, and its application to precautionary management procedures
}

\author{
Stephen A. Arnott*, Graeme D. Ruxton, Elvira S. Poloczanska \\ Division of Environmental \& Evolutionary Biology, Faculty of Biomedical \& Life Sciences, University of Glasgow, \\ Glasgow G12 8QQ, Scotland, UK
}

\begin{abstract}
Sandeels (sand lance) are important prey for fish, bird and mammal predators. In the North Sea, they are also the target of the region's largest 'single-species' fishery, with annual yields of ca. 0.8 million tonnes, mostly (>90\%) comprising the species Ammodytes marinus. This species is relatively short-lived, and has large, naturally occurring, population fluctuations that confound the use of traditional methods of fishery forecasting for their management. Here we present a stochastic age-structured model that describes the population dynamics of North Sea sandeels. Recruitment to the population occurs according to a stochastic, autocorrelated Ricker function. Uncertainty in the recruitment parameters was quantified by bootstrap analysis, leading to 3 different versions of the model that allowed a range of potentially viable recruitment scenarios to be explored. Monte Carlo simulations were performed under different fishing mortality levels, and the responses of the population assessed. The model is used to quantify recruitment and the likelihood of the sandeel spawning stock biomass falling below 600000 and $430000 \mathrm{t}$, which represent the precautionary and biomass limit levels, respectively, imposed by managers upon the stock.
\end{abstract}

KEY WORDS: Sandeel $\cdot$ Sand lance $\cdot$ Ammodytes marinus $\cdot$ North Sea $\cdot$ Industrial fishery $\cdot$ Population dynamics $\cdot$ Autocorrelation $\cdot$ Precautionary approach

\section{INTRODUCTION}

The lesser sandeel Ammodytes marinus (Raitt, 1934) is a vital species within the North Sea marine ecosystem, forming a trophic link between zooplankton and higher predators (Greenstreet 1996, Greenstreet et al. 1998). The population makes up 10 to $15 \%$ of the estimated total biomass of fishes in the North Sea and is eaten by numerous species of fishes (e.g. Sparholt 1990, Anon 1997), birds (e.g. Monaghan et al. 1989, Tasker \& Furness 1996, Wanless et al. 1998, Furness \& Tasker 2000) and mammals (e.g. Furness 1990, Pierce

\footnotetext{
* Present address: Marine Sciences Research Center, Stony Brook University, Stony Brook, New York, 11794-5000, USA.

E-mail: sarnott@ms.cc.sunysb.edu
}

et al. 1991, Tollit et al. 1997). Among the major sandeel predators taken into consideration by the International Council for the Exploration of the Sea's (ICES) North Sea multispecies assessment group, sandeels comprise ca. 40 to $60 \%$ of the fish biomass consumed and ca. 15 to $25 \%$ of the total biomass consumed in the North Sea (calculated from data in Anonymous 1997).

An industrial fishery for sandeels started to develop in the early 1950 s, increasing gradually to a yield of about 200000 metric tonnes in 1970. Thereafter, the fishery expanded rapidly: the mean annual landing was $482000 \mathrm{t}$ during the $1970 \mathrm{~s}, 734000 \mathrm{t}$ during the 1980s, and $836000 \mathrm{t}$ between 1990 and 1998. The fishery accounts for the largest single-species landing in the North Sea, with the highest on record being $1.14 \times$ $10^{6} \mathrm{t}$ in 1997 . The majority of the fish are taken by the Danish fleet (62 to $88 \%$ between 1990 and 1998), with 
smaller/occasional fisheries being operated by Norway (10 to $35 \%$ ), the UK, Faroes, Sweden and the Netherlands (Anonymous 1999a). Although there are 5 species of sandeel in the North Sea, more than $90 \%$ of the catch comprises Ammodytes marinus.

ICES assesses the North Sea sandeel stock on an annual basis. At present, there is no management objective set for the stock, which has had a spawning stock biomass $(S)$ fluctuating between 387000 and 2015000 t since 1976 (Fig. 1). The main catch comprises 1-group fish, with few fish living beyond 4 or $5 \mathrm{yr}$ of age. This fact, coupled with sandeels' high natural mortality rate, has led to doubts about the use of traditional short-term, deterministic stock-forecast methods for sandeels (Anonymous 1999a,b). A total allowable catch of 1 million t was set in 1998 to prevent further expansion of fishing effort. In 2000, a $20000 \mathrm{~km}^{2}$ area off the UK was closed to the fishery due to concern over its impact upon the breeding success of locally nesting seabirds that feed upon sandeels. Black-legged kittiwakes Rissa tridactyla are considered to be particularly sensitive to declines in local sandeel abundance during their breeding season (Harris \& Wanless 1990, 1997, Furness \& Tasker 2000) and ICES has recommended that fishing in the protected area should, in future, be linked to kittiwake breeding success.

This mirrors the concerns raised in Shetland during the late 1980s when seabird breeding success declined seriously due to successive years of low sandeel abundance. The local sandeel fishery (assessed separately from the North Sea population) was initially implicated (Monaghan 1992, Monaghan et al. 1992) and a fishing ban was imposed between 1991 and 1994. However, later studies suggested that the poor sandeel recruit-

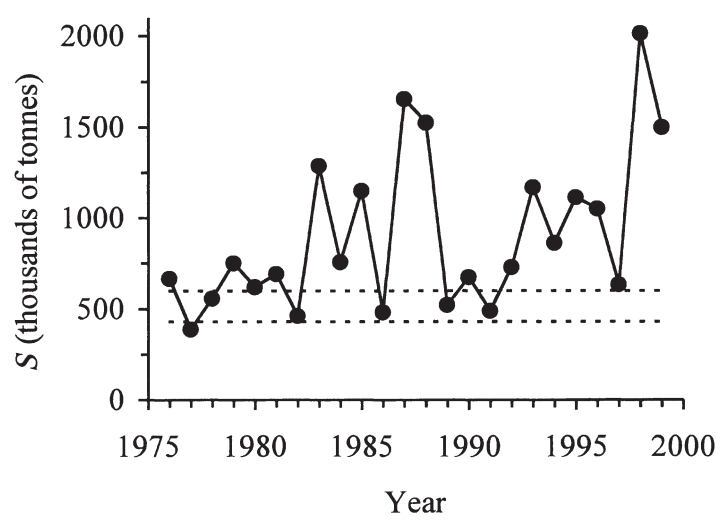

Fig. 1. Time series plot showing spawning stock biomass $(S)$ of sandeels in the North Sea between 1976 and 1999. Dotted lines represent the $B_{\mathrm{pa}}$ (top) and $B_{\lim }$ (bottom) levels recommended by the International Council for the Exploration of the Sea (600000 and $430000 \mathrm{t}$, respectively). (Data from Anonymous 1999a; see 'Introduction' for definitions) ment had mainly been due to unfavourable oceanic currents, which are responsible for transporting sandeel larvae to the region (Wright 1996).

Concern regarding the effects of sandeel fishing also extends to other predators, although these may be more difficult to detect or confirm. The majority of predation on sandeel in the North Sea is attributed to commercially important fishes such as mackerel, haddock, cod and saithe (Anonymous 1997), which themselves have been in decline since the 1960s, largely due to the fisheries aimed at them. Hence, their total consumption of sandeels is lower now than it was then, and this decrease tends to offset the concurrent growth of the industrial fishery (Anonymous 1999b, Furness 1999). The effects upon these predators of depleting sandeel availability are generally unknown (Furness 1999).

ICES advises that fishing mortality should not be allowed to increase because the consequences of removing a larger fraction of the food-biomass for other biota are unknown. The precautionary approach adopted by ICES in recent years establishes that, in order for a stock and its fishery to be within a safe biological limit, there should be a high probability that: (1) the $S$ is above the threshold at which recruitment is impaired, and (2) fishing mortality is not high enough to drive the $S$ to the threshold level. The biomass threshold is defined as $B_{\lim }$ (for 'limit') and in order to have a high probability of avoiding it, management advice should be taken before this threshold is approached. The $S$ below which management action should be taken is called $B_{\mathrm{pa}}$ (for 'precautionary approach') (Anonymous 1999c). $B_{\lim }$ and $B_{\mathrm{pa}}$ values for North Sea sandeels have been set at $430000 \mathrm{t}$ and 600000 t, respectively (Anonymous 1999a).

Management of exploited populations can be problematic in the face of non-linear intraspecific, interspecific and climatic interactions that affect their stability. Even in the absence of these factors, populations will fluctuate on account of the inherent discreteness of the individuals within them (Bjørnstad \& Grenfell 2001). Thus, management strategies that depend upon deterministic predictions, such as maximum sustainable yield, can be highly problematic since they depend upon precise knowledge of the population dynamics (Sæther et al. 1996).

Since deterministic forecast methods have been deemed unsuitable for North Sea sandeels (Anonymous 1999a,b), an alternative approach is proposed here that embodies the recorded variability in the sandeels' population dynamics. A range of recruitment functions has been derived by bootstrap analysis, and these are used as a basis for modelling the population. Crucially, the residuals about the recruitment functions are modelled stochastically, taking into account the nature of their autocorrelation 'colour', which can 
affect the likelihood of a population's extinction (Ripa \& Lundberg 1996). The population model also embodies stochastic mortality and weight-at-age functions derived from the most recent multi-species assessment of the North Sea (Anonymous 1997). Monte Carlo simulations are derived under different fishing mortality regimes in order to generate a time series of sandeel $S$ values. These results are used to determine the likelihood of violating the $B_{\mathrm{pa}}$ and $B_{\mathrm{lim}}$ thresholds under the different fishing regimes and recruitment assumptions.

\section{METHODS}

The model. Population structure, recruitment and mortality were calculated as follows.

Population structure: The population was divided into 0 (first year of life), 1, 2, 3, 4 and 5+ age classes, with progression from one class to the next occurring in January of each year. The initial population numbers entered in the model (see Table 1) were those estimated to be present in the North Sea at the beginning of 1983, according to ICES (Anonymous 1999a). Note, however, that due to its stochastic nature, the model is insensitive to the precise starting numbers entered. The area under consideration covers the North Sea (ICES Fishing Areas IVa, IVb and IVc), excluding Shetland, which is a separately assessed inshore fishery.

ICES considers the North Sea spawning stock to comprise those fish aged 2 and above, and so the same assumption was made here. $S$ was calculated in January of each year using a stochastic weight-at-age function derived from ICES' first half-of-year weight data (Anonymous 1999a). ICES uses separate weight-atage keys for sandeels from the southern North Sea and the northern North Sea, and so it was necessary to divide the model population between these 2 regions. For this purpose, the percentage of the population allocated to the south $\left(P_{\text {south }}\right)$ was initially set at $75 \%$, with the remaining $25 \%$ apportioned to the north, but in order to explore the model's sensitivity to this parameter, runs were also performed with $P_{\text {south }}$ adjusted to 50 and $25 \%$. Stochasticity about the mean weight at age was calculated as:

$$
W_{a, t}^{\prime}=\bar{W}_{a}+\theta_{a} \varepsilon_{a, t}
$$

where $W_{a, t}^{\prime}$ (constrained so as to always be $>0$ ) is the adjusted weight at age $a$ in year $t, \bar{W}_{a}$ is the mean weight at age, $\theta_{a}$ is the standard deviation about the mean weight at age, $\varepsilon_{a, t}$ and is a random normal deviate (mean $=0, \mathrm{SD}=1$ ). Details of $\bar{W}_{a}$ and $\theta_{a}$ values are given in Table 1.

Recruitment: Recruitment to the model population occurred at the beginning of July each year, the approximate time of year at which recruitment occurs in the North Sea (Macer 1965, Langham 1971), and the time at which the fishery assessments assume that 0-group fish arrive (Anonymous 1997, 1999a). Recruitment was simulated using a Ricker function (Hilborn \& Walters 1992), to which log-normal, autocorrelated stochastic residuals were added (see Eq. 4). The Ricker function was used because there is evidence of strong competition between established sandeels and new recruits (Furness 1999). The Ricker function took the form:

$$
R_{t}=a S_{t} \mathrm{e}^{-b S_{t}}
$$

where $R_{t}$ is number of recruits (billions) in July of year $t$, and $S_{t}$ is spawning stock biomass (thousands of $\mathrm{t}$ ) at the beginning of year $t$. Coefficients $a$ and $b$ were derived by least-squares regression using the linearised version of the model (Hilborn \& Walters 1992), where:

$$
\ln \left(\frac{R_{t}}{S_{t}}\right)=\ln (a)-b S_{t}
$$

The data used for fitting the North Sea recruitment function were taken from the most recent singlespecies virtual population analysis (SSVPA) performed by ICES (Anonymous 1999a) because it covered the longest time period possible (1976 to 1998) at the time of our study. Ninety-five percent confidence limits of coefficients $a$ and $b$ were derived using bootstrap methods (Manly 1997). Data points were randomly

\begin{tabular}{|c|c|c|}
\hline Parameter & & Unit \\
\hline \multicolumn{2}{|c|}{ Abundance at start of model run } & Billions \\
\hline \multirow[t]{6}{*}{ Age class } & 0 & 0.0 \\
\hline & 1 & 98.5 \\
\hline & 2 & 88.4 \\
\hline & 3 & 3.5 \\
\hline & 4 & 0.5 \\
\hline & $5+$ & 0.0 \\
\hline \multicolumn{2}{|c|}{ Weight-at-age $(g)$} & Mean (SD) \\
\hline \multicolumn{3}{|c|}{ Northern North Sea } \\
\hline \multirow[t]{4}{*}{ Age class } & 2 & $13.36(5.442)$ \\
\hline & 3 & $15.08(6.161)$ \\
\hline & 4 & $21.70(6.362)$ \\
\hline & $5+$ & $27.39(9.379)$ \\
\hline \multicolumn{3}{|c|}{ Southern North Sea } \\
\hline \multirow[t]{4}{*}{ Age class } & 2 & $10.38(1.664)$ \\
\hline & 3 & $13.48(1.834)$ \\
\hline & 4 & $16.95(2.062)$ \\
\hline & $5+$ & $20.21(3.124)$ \\
\hline \multicolumn{3}{|c|}{$\%$ of population in southern North Sea $\left(P_{\text {south }}\right)$} \\
\hline & & 75 (default) \\
\hline & & 50 \\
\hline & & 25 \\
\hline
\end{tabular}

Table 1. Sandeel population parameters used in the population model. See 'Methods' for details 
sampled (with replacement) to generate 10000 bootstrap data series (each containing 23 recruit- $S$ data points), for which solutions to $a$ and $b$ were calculated. The $95 \%$ confidence limits were then taken from the 2.5 and $97.5 \%$ values. These values were used to test the sensitivity of the population model to the recruitment parameters. Three separate versions of the population model were constructed. In Model 1, recruitment was modelled with the a coefficient set at its lower $95 \%$ confidence limit; in Model 2, a was set at the value of best fit; and in Model 3, a was set at its upper $95 \%$ confidence limit (see below for further details).

Autocorrelated, log-normally distributed stochasticity was added to the Ricker fit using the function:

$$
R_{t}^{\prime}=R_{t} \mathrm{e}^{\phi_{t}}
$$

where $R_{t}^{\prime}$ is the stochastically adjusted value of $R_{t}$ and $\phi_{t}$ is derived from the autocorrelation function:

$$
\phi_{t}=\alpha \phi_{t-1}+\beta \varepsilon_{t}
$$

in which $\varepsilon_{t}$ is a random normal deviate with mean $=0$ and SD = 1 (see Ripa \& Lundberg 1996). The autocorrelation function was used because $\log _{\mathrm{e}}$ residuals about the Ricker fit (Eq. 2) were significantly autocorrelated at a lag of $1 \mathrm{yr}(\mathrm{p}<0.05)$, and because the stock is known to comprise alternate years of high and low stock numbers (Anonymous 1999a). The autocorrelation coefficient, $\alpha$, was calculated according to Chatfield (1996):

$$
\alpha=\frac{C_{1}}{C_{0}}
$$

where

$$
c_{k}=\frac{1}{n-k} \sum_{t=1}^{n-k}\left(i_{t}-\bar{i}\right)\left(i_{t+k}-\bar{i}\right)
$$

The time lag (yr) is represented by $k, n$ is the number of years (23) in the time series, and $i_{t}$ is the $\log _{\mathrm{e}}$ residual at time $t$ from the Ricker function (Eq. 2). The coefficient $\beta$ in Eq. (5) was calculated from the function:

$$
\beta=\theta_{i} \sqrt{1-\alpha^{2}}
$$

where $\theta_{i}$ is the standard deviation of the $\log _{\mathrm{e}}$ residuals derived from the Ricker fit in Eq. 2.

The bootstrapped datasets that were generated for estimating the confidence limits of the Ricker coefficient do not maintain any of the autocorrelative timeseries structure possessed by the original ICES recruitment data because the bootstrapped data is drawn sequentially at random. Therefore, these datasets could not be used for calculating autocorrelation coefficients. Instead, each of the 10000 bootstrapped Ricker curves was fitted through the original ICES recruitment data. Autocorrelation coefficients were then calculated from the residual values that each curve produced. Thus, autocorrelation coefficients have been matched according to the shape of each curve that was fitted, but the confidence limits of autocorrelation coefficients for each individual curve have not been determined.

Mortality: Age-specific instantaneous natural mortality $\left(M_{1}\right.$ and $\left.M_{2}\right)$ and fishing mortality $(F)$ values were set according to annual values determined by the most recent ICES MSVPA (multi-species virtual population analysis) of the North Sea (Anonymous 1997; see present study Table 2). $M_{2}$ represents the portion of natural mortality attributable to predation, whilst $M_{1}$ represents the remaining 'unexplained' natural mortality. All virtual population analyses of North Sea sandeels by ICES assign an annual $M_{1}$ value of 0.2 to all age classes, and so this fixed value was also assigned throughout in our model. $M_{2}$ values are derived in the ICES MSVPA (Anonymous 1997) from estimates of predation by 10 principal predators (cod, whiting, saithe, North Sea mackerel, Western mackerel, haddock, gurnards, starry rays, seabirds, and 'other'; the mean values across several MSVPA years are used for the fixed $M_{2}$ values that are entered in the ICES SSVPA assessments). In our population model, $M_{2}$ fluctuated stochastically from year to year, such that:

$$
M_{2, a, t}^{\prime}=\bar{M}_{2, a}+\varepsilon_{t} \theta_{a}
$$

where $\mathrm{M}_{2, a, t}^{\prime}$ (constrained so as to always be $>0$ ) is the stochastically adjusted $M_{2}$ value for age class a in year $t, \bar{M}_{2, a}$ is the mean $M_{2}$ value for age class $a_{1} \varepsilon_{t}$ is a random normal deviate (mean $0, \mathrm{SD}=1$ ) in year $t$, and $\theta_{a}$ is the standard deviation about $\bar{M}_{2, a}$. The values $\bar{M}_{2, a}$ and $\theta_{a}$ were calculated from MSVPA data (Anonymous 1997) for the period 1983 to 1995 (see Table 2). Exploration of these data also revealed that the $M_{2}$ of sandeels aged 1 yr and older were correlated with one another within a given year, and so a correlation was forced between these age classes in the model (correlation coefficient, $\mathrm{r} \approx 0.8$ ).

$F^{\prime}{ }_{a, t}$ (the stochastically adjusted fishing mortality of age class $a$ in year $t$ ) was derived in the same manner as $M_{2, a, t}^{\prime}$ using $F$ values from Anonymous (1997) (see Table 2). No correlation was forced between age classes within a given year (since none was detected in the assessment data). Different fishing regimes were then imposed within the model by multiplying the age-specific fishing mortality in year $t$ by a parameter $\lambda$. Thus, when $\lambda=1.0$, the mean fishing mortality from all modelled years was the same as the mean in the North Sea MSVPA for the period 1983 to 1995 (Anonymous 1997). Additional runs were performed with $\lambda$ set at 0.0 and 0.5 (reduced fishing mortality) and at 1.5 and 2.0 (increased fishing mortality). 
The model was progressed in 1 mo time steps. At the end of each month, the number of sandeels of a given age that had died, and thus left the population, was calculated as:

$$
D_{a, m}=N_{a, m}\left[1-\exp \left(-Z_{a, t} / 12\right)\right]
$$

where $D_{a_{1} m}$ is the number of sandeels of age a that die in month $m, N_{a, m}$ is the number of sandeels of age $a$ alive at the beginning of month $m$ and $Z_{a, t}$ is the instantaneous coefficient of total mortality for age class $a$ in year $t$ (i.e. $M_{1}+M_{2, a, t}^{\prime}+F_{a, t}^{\prime}$ ).

Monte Carlo simulations. Monte Carlo simulations (Manly 1997) were performed under a range of different model conditions. In every instance, 20 simulations were run covering a total time period of $63 \mathrm{yr}$ each. During the first 13 yr of a simulation, mortality was set to the actual MSVPA values estimated for North Sea sandeels over the period 1983 to 1995 (Anonymous 1997), and $\lambda$ was set at 1.0. Each simulation then progressed for a further $50 \mathrm{yr}$ period, during which mortality was invoked stochastically (as described in the previous subsection), with $\lambda$ adjusted to the input value of interest. Thus, each simulation always ran with an initial period that mimicked the North Sea's recent mortality regime, and thereafter switched to a stochastic regime in which fishing mortality could be adjusted. The results that are presented below are derived from the output data for 20 to 63 yr. Mean number of recruits and $S$ were calculated from the $\log _{\mathrm{e}}$-transformed output data of the 20 simulations that were run under each set of conditions (values are presented in their back-transformed format). Responses of the modelled recruitment and $S$ to changes in mortality are expressed with respect to $Z_{1-2}$ (the mean long-term annual total mortality of Age Classes 1 and 2 combined, i.e. $\left[\bar{Z}_{1}+\bar{Z}_{2}\right] / 2$ ), since ICES uses 1 to 2 group mortality as a measure of fishing intensity in the North Sea (Anonymous 1999a), and the vast majority of the catch comprises these age classes.

\section{RESULTS}

\section{Bootstrap analysis of Ricker recruitment curve}

From the bootstrap analysis, the mean value of coefficient a (Eqs. 2 \& 3) was found to be 1.515. This was very similar to the value of best fit (1.516), which minimised the residual sum of squares in the linear regression (Eq. 3) using the ICES recruitment dataset. The $95 \%$ confidence limits of $a$, as determined from the 2.5 and 97.5 percentiles of the bootstrap results, were 0.800 and 2.412. However, residual sum of squares were greater at the lower $(0.800)$ confidence limit than at the upper (2.412) confidence limit (9.1 vs 8.3, respectively). This was reinforced by the fact that residual sum of squares increased steeply at values lower than 0.800 (see Fig. 2D).

For the purposes of modelling the sandeel population, 3 separate Ricker relationships were used in order to test the sensitivity of the population model to uncertainly in the recruitment coefficients. Ricker functions were formulated in which the initial slope of the curve (represented by coefficient $a$ ) was set at: Model 1: $a=0.800$ (lower 95\% confidence limit); Model 2: $a=1.516$ (best fit); Model 3: $a=2.412$ (upper $95 \%$ confidence limit).

Solutions to $a, b, \alpha$, and $\beta$ from each run of the bootstrap analysis were highly correlated (Fig. 2A-C). Therefore, once a had been set in Models 1, 2 and 3, coefficient $b$ was derived iteratively by minimising the sum of squares with respect to the original ICES stockrecruitment data, and $\alpha$ and $\beta$ were then calculated from the residuals. Full details of the coefficients used in each version of the model are presented in Table 2. The deterministic curves produced from Models 1, 2 and 3 are shown in Fig. 3A, and examples of stochastic fits under Model 2 conditions are shown in Fig. 3B.

\section{Recruitment responses to fishing mortality}

The recruitment outputs of the population model under the conditions of Models 1 to 3, and under different fishing mortality regimes are summarised in Table 3 \&
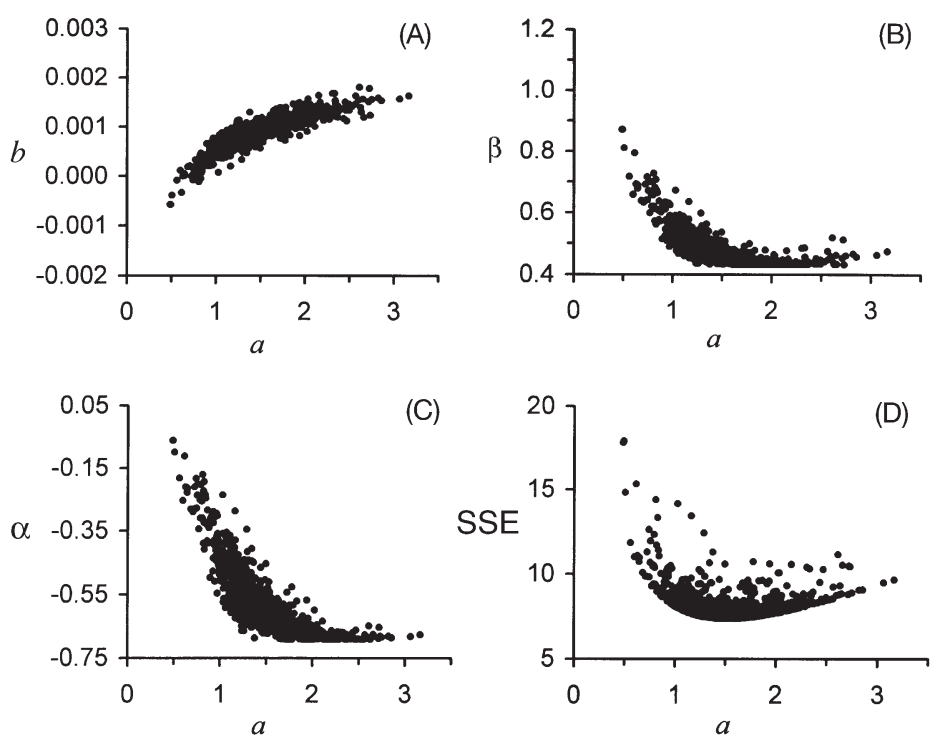

Fig. 2. Results from bootstrap analysis of the sandeel recruitment data. Relationships between Ricker coefficient $a$ and (A) Ricker coefficient $b$, (B) coefficient $\beta$ (see Eqs. 4 to 8), (C) autocorrelation coefficient $\alpha$ (see Eqs. 4 to 8), and (D) sum of squared errors (SSE) 
Fig. 4. Model 1 produced recruitment dynamics that were the most sensitive to changes in fishing mortality, predicting high (mean $>700$ billion) recruitment at very low fishing mortality levels and low (mean $<100$ billion) recruitment at the highest fishing mortality levels (Fig. 4A). Model 2 produced recruitment dynamics that were relatively insensitive to fishing regime, with highest mean recruitment (520 billion) occurring at intermediate fishing levels ( $\lambda=0.5$ to 1.0 , $Z_{1-2}=1.21$ to $1.45:$ Fig. $4 \mathrm{~B}$ ). Model 3 recruitment trends were opposite to those of Model 1, but were much less sensitive to changes in fishing regime (range $=400$ to 560 billion: Fig. 4C). Relative variability in recruitment (i.e. SD/mean) was always lowest when fishing mortality levels were minimised $(\lambda=0)$ and highest when fishing mortality was maximised $(\lambda=2.0)$.

Table 2. Annual mortality and recruitment values used in the population model (see 'Methods' for details)

\begin{tabular}{|c|c|c|}
\hline \multicolumn{2}{|l|}{ Parameter } & Unit \\
\hline \multicolumn{2}{|l|}{ Natural mortality } & Mean (SD) \\
\hline \multicolumn{2}{|l|}{$M_{1}$ All ages } & $0.20[0.00]$ \\
\hline \multirow[t]{6}{*}{$M_{2}$ Age class } & 0 & $1.3169(0.1748)$ \\
\hline & 1 & $1.0597(0.1249)$ \\
\hline & 2 & $0.5035(0.0325)$ \\
\hline & 3 & $0.6172(0.0442)$ \\
\hline & 4 & $0.4579(0.0492)$ \\
\hline & $5+$ & $0.5350(0.0614)$ \\
\hline \multicolumn{3}{|l|}{ Fishing mortality } \\
\hline \multirow[t]{6}{*}{$F \quad$ Age class } & 0 & $0.0160(0.0106)$ \\
\hline & 1 & $0.3608(0.1766)$ \\
\hline & 2 & $0.5668(0.3316)$ \\
\hline & 3 & $0.5699(0.2794)$ \\
\hline & 4 & $0.4394(0.3265)$ \\
\hline & $5+$ & $0.5484(0.4194)$ \\
\hline \multirow{5}{*}{\multicolumn{2}{|c|}{$\begin{array}{l}\text { Adjustment in fishing mortality } \lambda \\
\left({ }^{*} \text { default }\right)\end{array}$}} & 0.0 \\
\hline & & 0.5 \\
\hline & & $1.0^{*}$ \\
\hline & & 1.5 \\
\hline & & 2.0 \\
\hline \multicolumn{3}{|l|}{ Recruitment } \\
\hline \multirow{5}{*}{$\begin{array}{l}\text { Ricker Model } 1 \\
\text { (lower 95\% CI) }\end{array}$} & $a$ & 0.8001 \\
\hline & $b$ & 0.00037 \\
\hline & $\alpha$ & -0.3605 \\
\hline & $\beta$ & 0.5891 \\
\hline & $\theta_{t}$ & 0.6315 \\
\hline \multirow{5}{*}{$\begin{array}{l}\text { Ricker Model } 2 \\
\text { (best fit) }\end{array}$} & $a$ & 1.5161 \\
\hline & $b$ & 0.00096 \\
\hline & $\alpha$ & -0.6191 \\
\hline & $\beta$ & 0.4546 \\
\hline & $\theta_{t}$ & 0.5788 \\
\hline \multirow{5}{*}{$\begin{array}{l}\text { Ricker Model } 3 \\
\text { (upper } 95 \% \text { CI) }\end{array}$} & $a$ & 2.4122 \\
\hline & $b$ & 0.00140 \\
\hline & $\alpha$ & -0.6910 \\
\hline & $\beta$ & 0.4390 \\
\hline & $\theta_{t}$ & 0.6072 \\
\hline
\end{tabular}
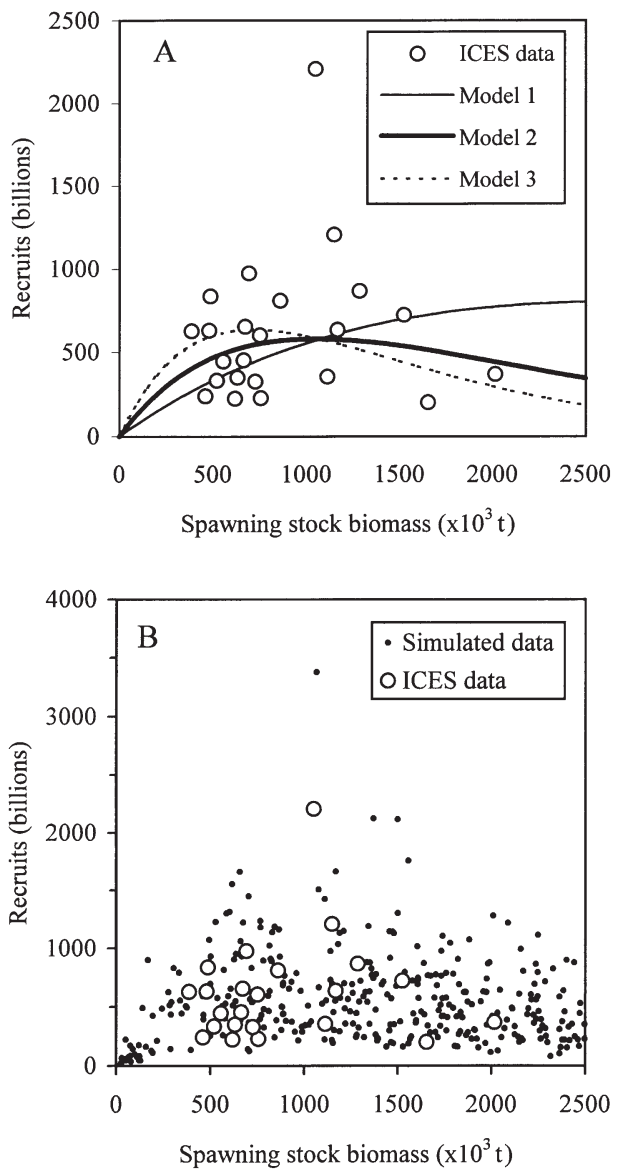

Fig. 3. Relationship between recruitment and $S$ for North Sea sandeels; (A) Recruitment as assessed by ICES (Anonymous 1999a), and deterministic Ricker relationships with coefficient $a$ set at the lower 95\% confidence limit (Model 1), best fit (Model 2), and upper 95\% confidence limit (Model 3); (B) example showing ICES recruitment data and 350 stochastically simulated recruitment values, derived from Model 2 using randomly chosen SSB data

Since the vast majority of the spawning stock biomass in the North Sea is believed to comprise 2 to 3-group sandeels (Macer 1966, Gauld \& Hutcheon 1990), and the majority of the catch comprises 1- to 2-group fish, fishing mortality in any one year may potentially affect recruitment the next year by curbing the number of sandeels that survive to spawn. However, analysis of data from SSVPA (Anonymous 1999a) and MSVPA (Anonymous 1997) assessments of the North Sea across the range of historically observed values indicate that no significant correlation exists between $Z_{1-2}$ one year and recruitment the next (Pearson product-moment correlation, recruitment data $\log _{\mathrm{e}}$-transformed: SSVPA, $\mathrm{r}=-0.084, \mathrm{p}=0.711, \mathrm{n}=$ 22, see Fig. 4; MSVPA, $\mathrm{r}=0.005, \mathrm{p}=0.984, \mathrm{n}=18$ ). This situation is most akin to that produced under Model 2 conditions of the population model. 

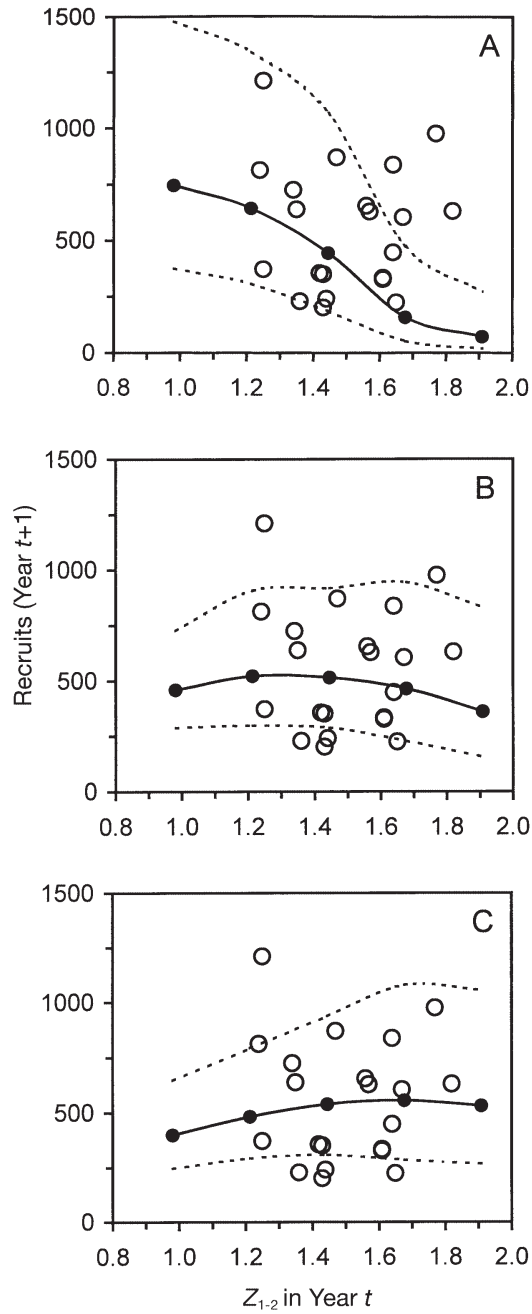

Fig. 4. Model output (•) showing long-term mean sandeel recruitment $\left(\times 10^{9}\right.$, back-transformed from $\log _{e}$ data $)$ with respect to long-term mean mortality under conditions of (A) Model 1, (B) Model 2 and (C) Model 3 (smoothed lines joining the data points have been inserted to illustrate general trends; dashed lines $=1 \mathrm{SD}$ ). Data are plotted against $Z_{1-2}$, the mean annual total mortality of 1 - and 2-group sandeels. The 5 simulated points in each plot are derived from the 5 different levels of fishing mortality that were tested in the model (from left to right, $\lambda$ set at $0.0,0.5,1.0,1.5,2.0$, respectively). (O) ICES SSVPA data for individual years covering the period 1976 to 1998 (Anonymous 1999a)

\section{Spawning stock biomass responses to fishing mortality}

Fig. 5 shows the model output for long-term mean $S$ $( \pm \mathrm{SD})$ under the different fishing regimes that were simulated. Models 1 to 3 all predicted that $S$ would decrease with increasing fishing mortality, but this relationship was steepest under Model 1 conditions $\left(3.25 \times 10^{6} \mathrm{t}\right.$ with no fishing, $91000 \mathrm{t}$ under the highest fishing regime: Fig. 5A). Model 3 had the narrowest mean $S$ range $\left(1.51 \times 10^{6}\right.$ t vs 536000 t; Fig. 5 C), and the range of Model 2 lay between these extremes $\left(1.80 \times 10^{6}\right.$ t vs 385000 t: Fig. 5B). Analysis of SSVPA data (Anonymous 1999a) and MSVPA data (Anonymous 1997) for the North Sea sandeel population supports the general prediction that higher mortality is associated with lower $S$ levels, since a strong negative correlation was found between $Z_{1-2}$ in one year and $S$ the year after (Pearson product-moment correlation, $S$ data $\log _{\mathrm{e}}$-transformed: SSVPA, $\mathrm{r}=-0.661$, $\mathrm{p}<0.001, \mathrm{n}=23$, see Fig. 5; MSVPA, $\mathrm{r}=-0.733$, $\mathrm{p}<0.0001, \mathrm{n}=19$ ).
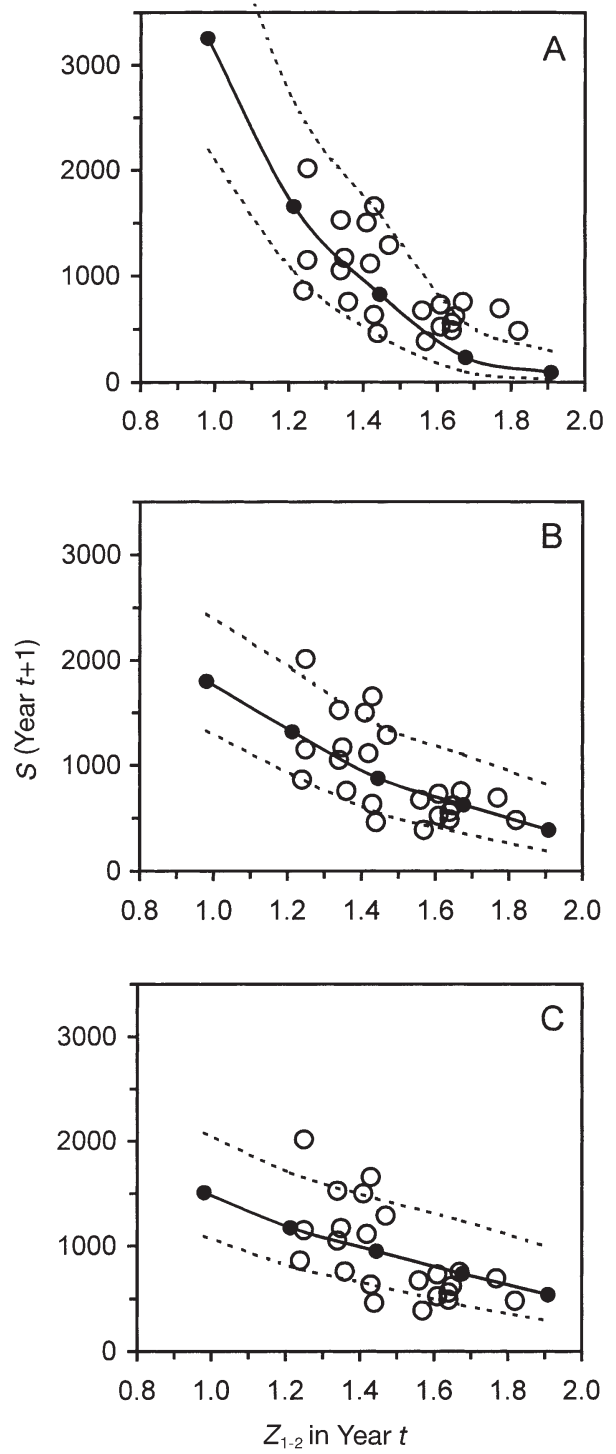

Fig. 5. Model output (•) showing long-term mean spawning stock biomass $\left(\times 10^{3} \mathrm{t}\right.$, back-transformed from $\log _{\mathrm{e}}$ data) with respect to long-term mean mortality under conditions of Model 1 (A), Model 2 (B) and Model 3 (C). (O) ICES SSVPA data for individual years covering the period 1976 to 1999 (Anonymous 1999a). Further details as in legend to Fig. 4 
Table 3. Percentage of runs ( $n=20$ for each combination of conditions) in which modelled recruitment was significantly different to 1976 to 1998 recruitment (as reported in the ICES single-species virtual population analysis SSVPA: Anonymous 1999a) under the conditions of Models 1, 2 and 3 exposed to different fishing regimes. Model Years 20 to 63 were compared to the ICES data using a Dunnett's multiple-comparison test, with a family error rate set at 0.05 . $\lambda$ represents the adjustment in fishing mortality applied within the model (see 'Methods' for details). $Z_{1-2}$ is the mean annual total mortality for sandeels aged 1 and 2

\begin{tabular}{|ccrcrcrc|}
\hline$\lambda$ & $\begin{array}{c}\text { Mean } Z \\
\text { (Ages 1-2) }\end{array}$ & \multicolumn{2}{c}{$\begin{array}{c}\text { Model 1: } a=0.80 \\
\text { (lower 95 \% CL) } \\
\%\end{array}$} & $\begin{array}{c}\text { Model 2: } a=1.52 \\
\text { Direction }\end{array}$ & $\begin{array}{c}\text { (best fit) } \\
\text { Direction }\end{array}$ & $\begin{array}{c}\text { Model 3: } a=2.41 \\
\text { (upper 95 \% CL) } \\
\text { \% }\end{array}$ & Direction \\
\hline 0.0 & $Z_{1-2}=0.98$ & 0 & - & 0 & - & 10 & Decrease \\
0.5 & $Z_{1-2}=1.21$ & 0 & - & 0 & - & 0 & - \\
1.0 & $Z_{1-2}=1.45$ & 10 & Decrease & 0 & - & 0 & - \\
1.5 & $Z_{1-2}=1.68$ & 85 & Decrease & 0 & - & 0 & - \\
2.0 & $Z_{1-2}=1.91$ & 100 & Decrease & 10 & Decrease & 0 & - \\
\hline
\end{tabular}

spells). When $Z_{1-2}$ was set at $1.45(\lambda=1.0)$, the longest $B_{\mathrm{pa}}$-depletion spells were $4 \mathrm{yr}$ (Model 1), 2 yr (Model 2) and 2 yr (Model 3) (each value is the median from 20 runs). The longest $B_{\text {lim-depleted spells were } 2,1}$ and $1 \mathrm{yr}$, respectively. At higher levels of fishing mortality, depletion spells became markedly more prolonged, but the effect was considerably more pronounced under Model 1 conditions than under Model 2 and 3 conditions (Fig. 7).

\section{Sensitivity of the model to southern versus northern allocation of the stock}

Since weight-at-age is allocated separately to the southern and northern sec-

\section{Likelihood of violating precautionary management limits}

Fishing regime influenced the proportion of years in which the modelled $S$ fell below the precautionary $B_{\mathrm{pa}}$ and $B_{\mathrm{lim}}$ levels currently recommended by ICES (i.e. 600000 and $430000 \mathrm{t}$, respectively). Under the North Sea's recent fishing regime $\left(\lambda=1.0, Z_{1-2}=1.45\right)$, Models 1 to 3 produced $S$ levels that violated $B_{\text {pa }}$ in 29, 21 and $15 \%$ of years, respectively, during Model Years 20 to 63 (Fig. 6A). The SSVPA assessment of the North Sea (Anonymous 1999a) estimates that, between 1983 and 1999, the North Sea $S$ fell below $B_{\mathrm{pa}}$ in 3 out of $17 \mathrm{yr}(18 \%)$, a frequency that does not differ significantly from any of the modelled frequencies (binomial test: Model 1, p =0.137; Model 2, p =0.232; Model 3, $\mathrm{p}=0.236$ ). With respect to $B_{\text {lim }}$, Models 1 to 3 produced $S$ levels that violated this limit in 16,7 and $4 \%$ of years, respectively (Fig. 6B), compared to none of the years over the period 1983-1999 for the North Sea SSVPA stock (comparison of SSVPA frequency against modelled frequencies: Model 1, p = 0.052; Model 2, $\mathrm{p}=$ 0.291; Model 3, p = 0.500). In the population model, the frequency with which $B_{\mathrm{pa}}$ and $B_{\text {lim }}$ were violated increased most steeply with respect to $Z_{1-2}$ under Model 1 conditions and least steeply under Model 3 conditions, but even at a mean $Z_{1-2}=1.21$ (when $\lambda=$ $0.5)$, all 3 models predicted that $S$ would occasionally ( 2 to $3 \%$ of years) fall below $B_{\text {pa }}$ (Fig. 6).

\section{Prolonged periods of continuously low $S$}

An analysis was performed on the maximum number of consecutive years during which $S$ continuously remained below $B_{\text {pa }}$ and $B_{\text {lim }}$ over Model Years 20 to 63 (referred to here as $B_{\mathrm{pa}}$-depleted and $B_{\mathrm{lim}}$-depleted tions of the North Sea in the population model, it was necessary to allocate a proportion of the model population to each region. The results presented so far assume that $P_{\text {south }}=75 \%$. The sensitivity of the model to regional allocation was tested by running simula-
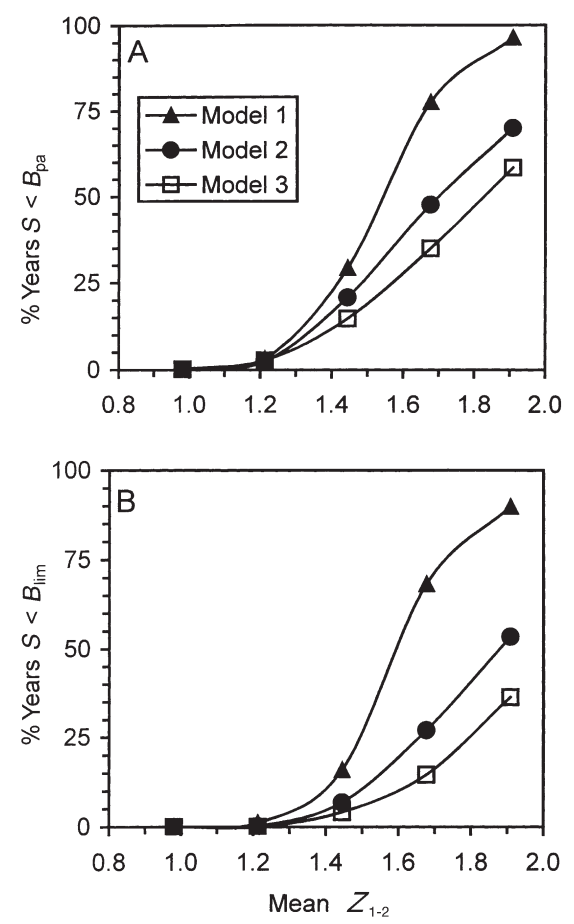

Fig. 6. Model Years 20 to 63: percentage of years (mean of 20 runs) in which $S$ fell below the precautionary management limits, as set by ICES. (A) Percentage of years below $B_{\text {pa }}$ $(600000 \mathrm{t}) ;\left(\right.$ B) Percentage of years below $B_{\lim }(430000 \mathrm{t})$. Values are plotted against $Z_{1-2}$, the mean annual total mortality of 1 - and 2-group sandeels. The 5 simulated points along each line plot are derived from the 5 different levels of fishing mortality that were tested in the model (from left to right, $\lambda$ set at $0.0,0.5,1.0,1.5,2.0$, respectively) 

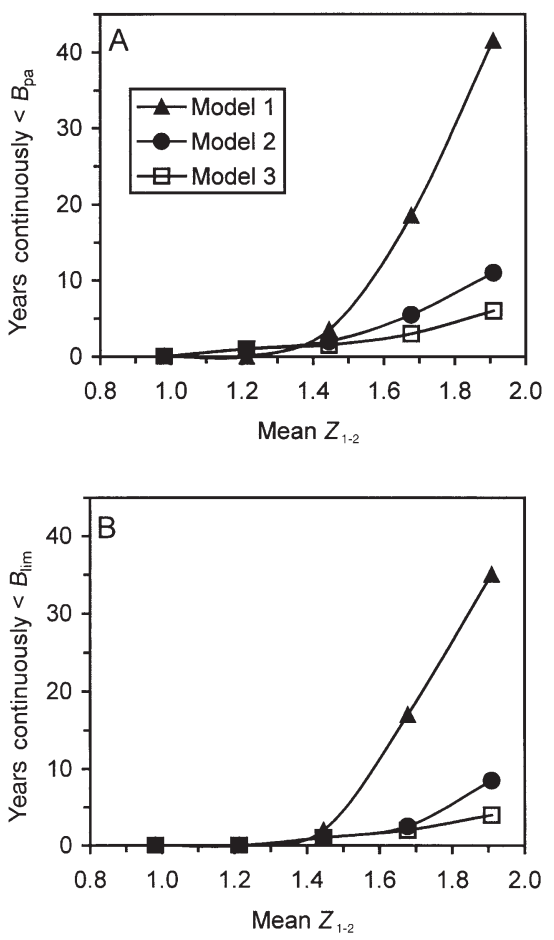

Fig. 7. Model Years 20 to 63: duration of the longest continuous period (median of 20 runs) in which $S$ remained below the precautionary management limits set by the International Council for the Exploration of the Sea. (A) years continuously below $B_{\text {pa }}\left(600000\right.$ tonnes). (B) Years continuously below $B_{\lim }$ (430000 tonnes). Further details as in legend to Fig. 6

tions with the stock, instead, being split with $P_{\text {south }}$ equal to 50 and $25 \%$.

Changes in the $P_{\text {south }}$ parameter had little overall effect upon the model results, with the effect being least pronounced in Model 3 and most pronounced in Model 1. The conclusions drawn from the models tended to be slightly more conservative (i.e. lower long term mean $S$ ) when $P_{\text {south }}$ was set at $75 \%$, and least conservative when set at $25 \%$. When $Z_{1-2}$ was maintained at $1.45(\lambda=1.0)$, adjusting $P_{\text {south }}$ from 75 to $25 \%$ in Models 1, 2 and 3 caused a change in mean $S$ from 824 to 1125,874 to 908 , and 949 to 957 thousand t, respectively.

\section{DISCUSSION}

Predicting population responses in a species with highly variable population dynamics can be problematic since the responses may be obscured by the variability of the data. The model presented here provides a framework for exploring population trends in a manner that is compatible with a precautionary management strategy, since the likelihood of violating precau- tionary stock limits can be estimated under a range of different population assumptions.

Sandeel abundance is highly variable from year-toyear in the North Sea. A major cause of this is the short life span of the species, such that recruitment strength in one year largely determines the total stock number the next year, and the spawning stock biomass the year after that. Furthermore, the residuals about the Ricker function were large and showed a significant negative autocorrelation at a lag of $1 \mathrm{yr}$. This is probably because the majority of the stock comprises 1-group fish (i.e. not the $S$ ), which occupy the same areas as newly settled fish and which therefore may compete with them for food and/or space, as well as possibly eating them (Yamada et al. 1998, Anonymous 1999b, Furness 1999).

Bootstrap analysis of the Ricker relationship produced recruitment responses ranging from Model 1 (shallow slope near the origin and high recruitment at high $S$ ) to Model 3 (steep initial slope and low recruitment at high $S$ : Fig. 3A). Model 1 apparently gave the poorest representation of sandeel recruitment, since the fitted Ricker function had the highest residual sum of squares, and simulations under Model 1 conditions (with $Z_{1-2}=1.45, \lambda=1.0$ ) produced recruitment estimates that were more likely to lie below the ICES North Sea assessment values (Table 3). However, a counter argument can made in favour of Model 1, since stock-recruitment relationships typically suffer from time-series bias, which can lead to density-dependent mortality (i.e. parameter $b$ in Eqs. 2 \& 3) being overestimated (Walters 1985, Myers \& Barrowman 1995). The bias arises because $S$ is dependent upon recruitment in previous years, such that it is not a truly independent variable. This gives more credence to Model 1 (which had lower density-dependence), and suggests that recruitment and $S$ could be more responsive to fishing mortality than might otherwise be expected (Figs. 4 \& 5).

A further problem with fitting any type of fish recruitment relationship is that the $S$ and recruitment values are estimates that contain inherent uncertainty, which can cause bias in the stock-recruitment relationships (Walters \& Ludwig 1981). This is especially problematic in species such as sandeels due to their high natural mortality rates, which are difficult to quantify and are assumed to remain constant in the SSVPA assessments. In addition, fishery-independent population surveys of sandeels are not routinely performed in the North Sea. Modelling of population dynamics under a variety of different assumptions is therefore important in assessing potential management strategies, and underlies the approach we have used here.

The precautionary management approach adopted by ICES aims to maintain the $S$ of North Sea sandeels 
above a $B_{\text {pa }}$ of $600000 \mathrm{t}$, taking subsequent action at lower levels to avoid further declines below the $B_{\lim }$ of $430000 \mathrm{t}$ (Anonymous 1999b). However, the short life cycle and high natural variability in sandeel numbers makes it difficult to predict just how often we may expect these limits to be violated. The approach used here attempts to quantify the extent of this variability, given the range of most likely conditions concerning the relationship between recruitment and $S$. As with all fishery populations, however, a major obstacle in making these predictions is the lack of knowledge concerning the nature of the recruitment versus $S$ relationship outside the observed range of historical data, especially at low $S$ levels. The model uses a range of relationships that fall within the $95 \%$ confidence limits of the Ricker function's slope near the origin, as determined by bootstrap analysis. In addition, time-dependent variability in recruitment, mortality and weight relationships are also encompassed stochastically within the model. Among the potential effects that are unaccounted for, perhaps the most serious is the possible emergence of an Allee effect at low population levels, whereby reproductive performance becomes compromised when $S$ is very low (Frank \& Brickman 2001, Hutchings 2001). It is biologically plausible that sandeels suffer from an Allee effect. For example, sandeels form large schools when they are feeding (Reay 1970), and it has been postulated that schooling species may suffer higher mortality as their numbers decline, since the anti-predation advantages of schooling (e.g. predator saturation) diminish with diminishing school size (Clark 1990). Investigations of recruitment dynamics across a large range of marine fish species have failed to detect this phenomenon (Myers et al. 1995, Liermann \& Hilborn 1997). However, Frank \& Brickman (2000) have shown that Allee effects may be undetectable at the stock assessment level, even if they exist at the sub-stock level. A useful extension of our study would be to explore the consequences of weak to moderate Allee effects with respect to the model predictions. At a basic level, one would expect the solutions from Model 1 to be more representative of Allee-type outcomes than Models 2 and 3 (since it integrates poorer recruitment at low $S$ levels), thus providing a more cautious management strategy at low stock levels.

Our population model supports the notion that reducing fishing mortality is an effective management method of increasing $S$ levels in North Sea sandeels. Moreover, analysis of SSVPA and MSVPA data indicates that the effects of this can be rapid, since a strong negative correlation was found between $Z_{1-2}$ in one year and $S$ the year after (Fig. 5). In terms of maintaining the long-term mean $S$ above the $B_{\mathrm{pa}}$, Models 1 to 3 predict that mean $Z_{1-2}$ should remain below ca. 1.5, 1.7 and 1.9 respectively (Fig. 5). However, at these fishing levels, Models 1 to 3 all predict that natural fluctuations in the population would still drive the $S$ below $B_{\text {pa }}$ in about $50 \%$ of years, and below $B_{\text {lim }}$ in about 25 to $30 \%$ of years (Fig. 6). This is unacceptable, because it relies heavily upon recruitment processes outside the historically observed $S$ range for the North Sea, and some depleted spells may persist for several consecutive years (Fig. 7). If we accept that $S$ may fall below $B_{\mathrm{pa}}$ in about $1 \%$ of years, mean $Z_{1-2}$ would need to be ca. 1.15 under all 3 model conditions. For a less stringent target of $5 \%$ of years, mean $Z_{1-2}$ would need to be less than or equal to ca. 1.25 . If we accept that $S$ may fall below $B_{\text {pa }}$ in about $10 \%$ of years, then mean $Z_{1-2}$ values would need to be ca. $1.30,1.32$ and 1.37 under the conditions of Models 1, 2 and 3, respectively. This latter case would result in $B_{\text {lim-depletion in }}$ approximately 5,2 and $2 \%$ of years, respectively, but one would expect both $B_{\mathrm{pa}}$ - and $B_{\text {lim }}$-depleted periods to be transient (1 yr, occasionally $2 \mathrm{yr}$ ) rather than persistent.

Since total sandeel mortality is the sum of natural mortality plus fishing mortality, the results of the model depend upon natural mortality of each age group fluctuating about a stable mean value. According to the ICES data (Anonymous 1997), the natural mortality of sandeels did not increase or decrease significantly over the period 1983 to 1995 (the period from which the values in Table 2 were derived). No MSVPA runs have been made since then, and so more recent natural mortality trends remain unknown. Due to the importance of predation mortality in sandeels, one would expect management policies that aim to increase the abundance of higher predator species in the North Sea to require an adjustment in sandeel fishing mortality so as to balance the overall levels of mortality they experience.

There has been much speculation concerning the trophic effects of sandeel fishing upon sandeel predators. Based on values derived from the ICES MSVPA (Anonymous 1997), more than $80 \%$ of the sandeel biomass consumed within the North Sea comprises either 0-group or 1-group sandeels. Whilst fishing will have an immediate affect upon the availability of sandeels as prey by removing them from the system, it could also affect future availability by affecting recruitment. According to the different sets of conditions that we modelled (i.e. Models 1 to 3), our results indicate that recruitment responses to fishing are difficult to predict. Model 1 predicted that mean recruitment would be greatly enhanced at low fishing levels and severely compromised at high fishing levels (Fig. 4A, Table 3), but this was not evident with Models 2 and 3 (Fig. 4B,C).

Recent investigations into North Sea sandeels suggest that they may comprise up to 5 or 6 distinct sub- 
populations, with low rates of interchange between them (Pedersen et al. 1999). This is partly due to the patchwork of suitable habitat areas that exist (Wright et al. 2000), and partly due to the water circulation patterns that prevail during the larval dispersal stage in spring (Proctor et al. 1998). At other stages of the life cycle, dispersal opportunities are thought to be minimal because sandeels tend to remain in an area once they have settled (Kunzlik et al. 1986), and their eggs are demersal (Reay 1970). The model presented here makes no attempt to predict localised subpopulation conditions, concentrating solely on the North Sea level. Although overall fishing levels may be kept within specified boundaries, future studies need to address this issue because uneven fishing effort between regions may drive localised sub-populations to dangerously low levels, even though the overall population level appears to be within acceptable limits (Frank \& Brickman 2001). An additional consideration, not explored here, is the potential influence of climatic conditions. If recruitment is affected by processes such as temperature or sea circulation patterns, persistent changes in these variables will cause instability in the sandeel population processes accounted for here.

Acknowledgements. We would like to thank Drs. Peter Wright and Henrik Jensen for their helpful collaboration during this project, as well as their respective co-workers at the Marine Laboratory Aberdeen (Scotland) and Danish Institute for Fisheries Research (Charlottenlund). Dr. Stephen Munch, Prof. Robert Furness and Dr. Jan Lindström provided helpful comments on the manuscript, as did 5 anonymous referees. Financial support was provided by the European Commission.

\section{LITERATURE CITED}

Anonymous (1997) Report of the multispecies assessment working group. ICES CM 1997 Assess 16:1-235

Anonymous (1999a) Report of the working group on the assessment of demersal stocks in the North Sea and Skagerrak. ICES CM 2000/ACFM 7:547-590

Anonymous (1999b) Report of the study group on effects of sandeel fishing. ICES CM 1999/ACFM 19:1-12

Anonymous (1999c) Report of the Int Counc Explor Sea Advisory Committee on Fishery Management. ICES Coop Res Rep 236:4-5

Bjørnstad ON, Grenfell BT (2001) Noisy clockwork: time series analysis of population fluctuations in animals. Science 293:638-643

Chatfield C (1996) The analysis of time series: an introduction. Chapman \& Hall, London

Clark CW (1990) Mathematical bioeconomics. The optimal management of renewable resources, 2nd edn. Wiley, New York

Frank KY, Brickman D (2000) Allee effects and compensatory population dynamics within a stock complex. Can J Fish Aquat Sci 57:513-517
Frank KY, Brickman D (2001) Contemporary management issues confronting fisheries science. J Sea Res 45:173-187

Furness RW (1990) A preliminary assessment of the quantities of Shetland sandeels taken by seabirds, seals, predatory fish and the industrial fishery in 1981-1983. Ibis 132: 205-217

Furness RW (1999) Does harvesting a million metric tonnes of sand lance per year from the North Sea threaten seabird populations? In: Ecosystems approaches for fisheries management. University of Alaska Sea Grant College Program Rep No. 98-01, University of Alaska, Fairbanks, p 407-424

Furness RW, Tasker ML (2000) Seabird-fishery interactions; quantifying the sensitivity of seabirds to reductions in sandeel abundance, and identification of key areas for sensitive seabirds in the North Sea. Mar Ecol Prog Ser 202: 253-264

Gauld JA, Hutcheon JR (1990) Spawning and fecundity in the lesser sandeel, Ammodytes marinus Raitt, in the northwestern North Sea. J Fish Biol 36:611-613

Greenstreet SPR (1996) Estimation of the daily consumption of food by fish in the North Sea in each quarter of the year. Scott Fish Res Rep 55:1-16 \& tables

Greenstreet SPR, McMillan JA, Armstrong E (1998) Seasonal variation in the importance of pelagic fish in the diet of piscivorous fish in the Moray Firth, NE Scotland: a response to variation in prey abundance? ICES J Mar Sci 55: 121-133

Harris MP, Wanless S (1990) Breeding success of kittiwakes Rissa tridactyla in 1986-88: evidence for changing conditions in the northern North Sea. J Appl Ecol 27:172-187

Harris MP, Wanless S (1997) Breeding success, diet and brood neglect in the kittiwake (Rissa tridactyla) over an 11-year period. ICES J Mar Sci 54:615-623

Hilborn R, Walters CJ (1992) Quantitative fisheries stock assessment: choice, dynamics and uncertainty. Chapman \& Hall, London

Hutchings JA (2001) Conservation biology of marine fishes: perceptions and caveats regarding assignment of extinction risk. Can J Fish Aquat Sci 58:108-121

Kunzlik PA, Gauld JA, Hutcheon JR (1986) Preliminary results of the Scottish sandeel tagging project. ICES CM (Demersal Fish Comm) 1986/ G:7:1-6

Langham NPE (1971) The distribution of larval sand-eels (Ammodytidae) in Scottish waters. J Mar Biol Assoc UK 51:697-707

Liermann M, Hilborn R (1997) Depensation in fish stocks: a hierarchic Bayesian meta-analysis. Can J Fish Aquat Sci 54:1976-1984

Macer CT (1965) The distribution of larval sand eels (Ammodytidae) in the southern North Sea. J Mar Biol Assoc UK 45:187-207

Macer CT (1966) Sandeels (Ammodytidae) in the southwestern North Sea: their biology and fishery. Fish Investig Ser II Mar Fish GB Minist Agric Fish Food 24(6):1-55

Manly BFJ (1997) Randomization, bootstrap and Monte Carlo methods in biology. Chapman \& Hall, London

Monaghan P (1992) Seabirds and sandeels: the conflict between exploitation and conservation in the northern North Sea. Biodivers Conserv 1:98-111

Monaghan P, Uttley JD, Burns MD, Thaine C, Blackwood J (1989) The relationship between food supply, reproductive effort and breeding success in arctic terns Sterna paradisaea. J Anim Ecol 58:261-274

Monaghan P, Uttley JD, Burns MD (1992) Effects of changes in food availability on reproductive effort in artic terns Sterna paradisaea. Ardea 80:70-81

Myers RA, Barrowman NJ (1995) Time series bias in the esti- 
mation of density-dependent mortality in stock-recruitment models. Can J Fish Aquat Sci 52:223-232

Myers RA, Barrowman NJ, Hutchings JA, Rosenberg AA (1995) Population dynamics of exploited fish stocks at low population levels. Science 269:1106-1108

Pedersen SA, Lewy P, Wright P (1999) Assessments of the lesser sandeel (Ammodytes marinus) in the North Sea based on revised stock divisions. Fish Res 41:221-241

Pierce GJ, Thompson PM, Miller A, Diack JSW, Miller D (1991) Seasonal variation in the diet of common seals (Phoca vitulina) in the Moray Firth area of Scotland. J Zool (Lond) 223:641-652

Proctor R, Wright PJ, Everitt A (1998) Modelling the transport of larval sandeels on the north-west European shelf. Fish Oceanogr 7:347-354

Reay PJ (1970) Synopsis of biological data on North Atlantic sand eels of the genus Ammodytes. FAO Fish Synop 82: $1-52$

Ripa J, Lundberg P (1996) Noise colour and the risk of population extinctions. Proc R Soc Lond B 263:1751-1753

Sæther BE, Engen S, Lande R (1996) Density-dependence and optimal harvesting of fluctuating populations. Oikos 76: $40-46$

Sparholt H (1990) An estimate of the total biomass of fish in the North Sea. J Cons Int Explor Mer 46:200-210

Tasker ML, Furness RW (1996) Estimation of food consump-

Editorial responsibility: Otto Kinne (Editor),

Oldendorf/Luhe, Germany tion by seabirds in the North Sea. In: Hunt GI, Furness RW (eds) Seabird/fish interactions, with particular reference to seabirds in the north sea. ICES Coop Res Rep 216: $6-42$

Tollit DJ, Greenstreet SPR, Thompson PM (1997) Prey selection by harbour seals, Phoca vitulina, in relation to variations in prey abundance. Can J Zool 75:1508-1518

Walters CJ (1985) Bias in the estimation of functional relationships from time-series data. Can J Fish Aquat Sci 42: 147-149

Walters CJ, Ludwig D (1981) Effects of measurement errors on the assessment of stock-recruitment relationships. Can J Fish Aquat Sci 38:704-710

Wanless S, Harris M, Greenstreet SPR (1998) Summer consumption of sandeels by seabirds in the Firth of Forth, Scotland. ICES J Mar Sci 55:1141-1151

Wright PJ (1996) Is there a conflict between sandeel fisheries and seabirds? A case study at Shetland. In: Greenstreet SPR, Tasker ML (eds) Aquatic predators and their prey. Blackwell Scientific Publications, Oxford

Wright PJ, Jensen H, Tuck I (2000) The influence of sediment type on the distribution of the lesser sandeel Ammodytes marinus. J Sea Res 44:243-256

Yamada H, Tsumoto K, Kuno M (1998) Cannibalistic mortality of larval sand eel Ammodytes personatus by adults in Ise Bay, central Japan. Nippon Suisan Gakkaishi 64:807-814

Submitted: July 18, 2001; Accepted: November 8, 2001 Proofs received from author(s): May 14, 2002 